\title{
Niche-Specificity and the Variable Fraction of the Pectobacterium Pan-Genome
}

\author{
J. D. Glasner, ${ }^{1}$ M. Marquez-Villavicencio, ${ }^{2}$ H.-S. Kim, ${ }^{2}$ C. E. Jahn, ${ }^{2}$ B. Ma, ${ }^{1}$ B. S. Biehl, ${ }^{1}$ A. I. Rissman, ${ }^{1}$ \\ B. Mole,${ }^{3}$ X. Yi, ${ }^{4}$ C.-H. Yang, ${ }^{4}$ J. L. Dangl, ${ }^{3,5,6,7}$ S. R. Grant,,${ }^{5,6}$ N. T. Perna, ${ }^{1}$ and A. O. Charkowski ${ }^{2}$ \\ ${ }^{1}$ Genome Center of Wisconsin and ${ }^{2}$ Department of Plant Pathology, University of Wisconsin-Madison, Madison, WI 53706, \\ U.S.A.; ${ }^{3}$ Department of Microbiology and Immunology, University of North Carolina at Chapel Hill, Chapel Hill, NC 27599, \\ U.S.A.; ${ }^{4}$ Department of Biological Sciences, University of Wisconsin-Milwaukee, Milwaukee, WI 53211, U.S.A.; ${ }^{5}$ Department \\ of Biology, ${ }^{6}$ Curriculum in Genetics, and ${ }^{7}$ Carolina Center for Genome Sciences, University of North Carolina at Chapel Hill
}

Submitted 11 April 2008. Accepted 11 August 2008.

\begin{abstract}
We compare genome sequences of three closely related softrot pathogens that vary in host range and geographical distribution to identify genetic differences that could account for lifestyle differences. The isolates compared, Pectobacterium atrosepticum SCRI1043, $P$. carotovorum WPP14, and $P$. brasiliensis 1692, represent diverse lineages of the genus. $P$. carotovorum and $P$. brasiliensis genome contigs, generated by 454 pyrosequencing ordered by reference to the previously published complete circular chromosome of $\boldsymbol{P}$. atrosepticum genome and each other, account for $96 \%$ of the predicted genome size. Orthologous proteins encoded by $P$. carotovorum and $P$. brasiliensis are approximately 95\% identical to each other and $92 \%$ identical to $P$. atrosepticum. Multiple alignment using Mauve identified a core genome of $3.9 \mathrm{Mb}$ conserved among these Pectobacterium spp. Each core genome is interrupted at many points by species-specific insertions or deletions (indels) that account for approximately 0.9 to $1.1 \mathrm{Mb}$. We demonstrate that the presence of a $h r p K$-like type III secretion system-dependent effector protein in $P$. carotovorum and $P$. brasiliensis and its absence from $P$. atrosepticum is insufficient to explain variability in their response to infection in a plant. Additional genes that vary among these species include those encoding peptide toxin production, enzyme production, secretion proteins, and antibiotic production, as well as differences in more general aspects of gene regulation and metabolism that may be relevant to pathogenicity.
\end{abstract}

Additional keywords: Erwinia, host range, soft rot.

Comparative genomics can reveal physiological and functional variation among bacteria that provides insight into their ability to exploit distinct ecological niches. For plant-pathogenic bacteria, key factors related to interaction with a plant host have emerged from comparisons with closely related animal-associated bacteria. For example, identification of gene clusters, or islands, that distinguish a single plant-pathogenic

Corresponding author: J. D. Glasner; Telephone: (608) 890-0171; Fax: (608) 265-9485; E-mail: jglasner@wisc.edu

Nucleotide sequence data for the assembled contigs are available in the GenBank database under accession numbers ABVX00000000 and ABVY00000000.

* The $\boldsymbol{e}$-Xtra logo stands for "electronic extra" and indicates that a supplementary figure is published online.
Pectobacterium genome from those of other enterobacteria that infect animals, such as Escherichia and Salmonella spp., revealed known and novel virulence factors, many of which are also found in more distantly related plant pathogens (Bell et al. 2004; Toth et al. 2006). Comparison of more closely related genomes can be particularly useful for illuminating niche adaptation, in part because the level of observed genetic variation is lower, simplifying reconstruction of both the evolutionary history and the phenotypic consequences of individual polymorphisms. Intraspecific comparisons of genomes from strains of both Pseudomonas syringae and Xanthomonas campestris with diverse host ranges revealed differences, including the type and number of type III secreted proteins (Feil et al. 2005; Joardar et al. 2005; Thieme et al. 2005). These can affect host range either by suppressing host defenses and enabling the growth of a pathogen or, conversely, they can trigger a strong resistance response blocking pathogen growth if an individual type III secreted protein is recognized by a cognate resistance protein in the host (Jones and Dangl 2006).

There are no previous intraspecific genome sequence comparisons for plant-associated enterobacteria; however, several groups of animal-associated enterobacteria have been sampled fairly extensively. Early comparisons revealed that only $40 \%$ of the total distinct protein-coding sequences are shared among the model Escherichia coli K12 strain, an enterohemorrhagic strain, and a uropathogenic strain (Welch et al. 2002), despite the fact that over $3.5 \mathrm{Mb}$ of the 4.5 - to $5.5-\mathrm{Mb}$ core genome is conserved among all three. This pattern has been observed in other groups of bacteria (Kettler et al. 2007; Tettelin et al. 2005), leading to the concept of a pan-genome, or the complete collection of genes in the species, only a fraction of which are found in any given strain. Importantly, as additional genomes (lineages) of a species are added to comparisons, the fraction of genes conserved, or core genome, declines relatively slowly for most bacteria, reflecting the relative stability of core metabolic and information-processing-related gene content. In contrast, some "cosmopolitan" species, such as E. coli and Streptococcus agalactiae, have a much larger and dynamic pan-genome, with the variable fraction composed of the sum total of many distinct lineage-specific gene islands, acquired through horizontal gene transfer. Mathematical models predict that even relatively wellsampled lineages such as $E$. coli will continue to yield novel genes as more strains are sequenced (Willenbrock et al. 2007). For plant-pathogenic enterobacteria with one published genome sequence, characterization of the pan-genome is in its infancy.

The soft rot pectobacteria (previously known as Erwinia carotovora) are economically important plant-pathogenic entero- 
bacteria. Pectobacterium spp. cause a spectrum of disease symptoms (termed wilt, soft rot, and blackleg) on a wide range of monocot and dicot host plants. These diseases are responsible for large economic losses during potato and ornamental production. Pectobacterium spp. have been isolated from numerous plant hosts, soil, and both surface and ground water (McCarter-Zorner et al. 1984, 1985). Pectobacterium spp. have also been found in association with a variety of invertebrates, ranging from fruit flies to snails (Harrison et al. 1977; Molina et al. 1974; Phillips and Kelman 1982). These invertebrates play an important role in the spread of soft rot bacteria between plant hosts and may also respond to the plant pathogen. For example, Basset and associates (2000) showed that fruit flies have an immune response when inoculated with Pectobacterium spp.

The genus Pectobacterium was recently resurrected and four E. carotovora subspecies were renamed as different Pectobacterium spp.: Pectobacterium atrosepticum, P. betavasculorum, $P$. carotovorum, and $P$. wasabiae (Gardan et al. 2003). Concurrently, a potential fifth species, originally named $E$. carotovora subsp. brasiliensis, was described as causing blackleg on potato in Brazil (Duarte et al. 2004). This species is phylogenetically distinct from the other four Pectobacterium spp. (Ma et al. 2007) and will be referred to herein as P. brasiliensis. The pathogens $P$. carotovorum, $P$. atrosepticum, $P$. brasiliensis, and $P$. wasabiae all cause disease on potato. Multiple species may cause disease in the same field and even on the same individual plant. $P$. carotovorum is found in many climates worldwide, $P$. atrosepticum is found in cool climates worldwide, and P. brasiliensis has only been reported in Brazil, Israel, and the United States but is likely to have a wider distribution (Ma et al. 2007). Of the potato-infecting species, $P$. carotovorum, $P$. brasiliensis, and $P$. wasabiae have all been reported to cause disease on other plant species and, thus, are broad-host-range pathogens, whereas $P$. atrosepticum appears to be limited to potato and closely related solanaceous crops. The genetic differences that limit the host range of $P$. atrosepticum compared with other Pectobacterium spp. are unknown.

In order to identify variation between subspecies that could provide clues to the nature of differences in host range, nutritional requirements, and species niches in the pectobacteria, we compared the genome sequences of three isolates that were phlyogentically well distributed. A phylogenetic analysis based on sequencing fragments of seven housekeeping genes from bacterial soft rot isolates collected from diverse locations around the world revealed that the Pectobacterium spp. could be classified into a monophyletic group distinct from the broad-hostrange soft rot pathogen Dickeya sp. (Erwinia chrysanthemi) and the tree pathogen Brenneria sp. The pectobacteria could be divided into five clades related by monophyletic descent (Ma et al. 2007). We chose the previously sequenced strain $P$. atrosepticum SCRI1043 representing clade V, $P$. carotovorum WPP14 representing clade II, and P. brasiliensis 1692 representing clade I. Conserved genes from these species were, on average, $95 \%$ identical. This degree of homology allowed us to assemble multiple sequence contigs derived by 454-platform pyrosequencing (454 Life Sciences, Branford, CT, U.S.A.) and Newbler analysis of genomic DNA from $P$. brasiliensis and $P$. carotovorum into ordered genome sequences by alignment with the genome of $P$. atrosepticum SCRI1043. Although we used the P. atrosepticum SCRI1043 genome to establish the structure of the other two genomes, the depth of sequence economically available with pyrosequencing allowed us to identify and position genes unique to each species as well as conserved sequences.

Comparison of the three genomes revealed a common core genome (representing approximately $80 \%$ of the nucleotides in each species) dotted with islands carrying diverse sequences.
The genes in unique islands were enriched for proteins of DNA replication, mostly of phage origin, and in regulatory genes. Unlike the xanthomonads and Pseudomonas syringae, and even the blight-causing E. amylovora (Triplett et al. 2006), the predicted type III secreted proteins were highly conserved within the group. Variability that could be associated with differences in host range was seen in genes for type IV secretion systems (T4SS), putative phytotoxins, taxis and motility genes, and cell surface proteins.

\section{RESULTS AND DISCUSSION}

We used 454-platform massively parallel pyrosequencing (Margulies et al. 2005) to generate draft genome sequences for Pectobacterium carotovorum and $P$. brasiliensis. Comparisons with a published complete genome for $P$. atrosepticum and with each other allowed us to order and orient the large number of contigs onto a scaffold based on the P. atrosepticum sequence, thereby constructing virtual genomes for $P$. carotovorum and $P$. brasiliensis and facilitating examination of higher order features, such as the presence, absence, or rearrangement of gene islands (Fig. 1).

\section{Assembly and ordering contigs in the draft genomes.}

Summary statistics are shown in Table 1 . Three runs of the 454 GS20 instrument on a DNA preparation for $P$. carotovorum resulted in $116,320,270 \mathrm{bp}$ of usable sequence, or 23.3fold coverage of the genome assuming a final size of $5 \mathrm{Mb}$, similar to $P$. atrosepticum and most other enterobacteria. Two runs using the same instrumentation yielded 86,099,090 bp and a level of 17.2-fold coverage for P. brasiliensis. De novo assembly for each genome was performed using the standard Newbler assembler, resulting in 4,746,006 and 4,775,163 bp in contigs greater than $500 \mathrm{bp}$ in length for $P$. carotovorum and $P$. brasiliensis, respectively. We employed two approaches to predict the order and orientation of the large number of contigs from each draft genome, Projector 2.0 (van Hijum et al. 2005) and Mauve 2.0 (Darling 2004). Projector 2.0 uses BLAST searches of strategic segments of each contig against a complete (or draft) reference genome to predict their relative locations and also outputs a list of polymerase chain reaction (PCR) primer pairs designed to link adjacent contigs. We tested 188 pairs of primers with $P$. carotovorum and confirmed 84 predicted contig linkages (data not shown). It is likely that more could be confirmed by optimizing PCR conditions.

Upon aligning the Projector 2.0 ordered contig sets for both draft genomes with the complete $P$. atrosepticum genome, we observed that Mauve detected additional contigs that could be ordered, including several cases where the $P$. carotovorum and $P$. brasiliensis contigs could be ordered relative to each other even if they were not homologous to regions of $P$. atrosepticum. Starting with the Projector 2.0 ordered set, we iteratively aligned and reordered contigs until no additional members of existing locally collinear blocks were found. After running both Projector 2.0 and Mauve, order and orientation can be predicted for a total of 273/731 $P$. carotovorum contigs and 169/1370 P. brasiliensis contigs. These ordered contigs account for 96.6 and $96.8 \%$ of their respective genomes. Mauve alignments for the unordered and ordered contig sets are compared in Figure 1. The final alignment of ordered contigs is available through ASAP and was used for a variety of the analyses described below.

\section{Comparison of $\boldsymbol{P}$. carotovorum draft genome with physical chromosome map.}

A preliminary physical map of the $P$. carotovorum chromosome was constructed using restriction enzyme mapping, 
mutagenesis, and DNA hybridization (Yap et al. 2004), and this map was compared with the assembled draft sequence. Yap and associates (2004) digested P. carotovorum genomic DNA with I-CeuI, which recognizes a conserved sequence in bacterial 23S rRNA genes, and observed seven I-CeuI fragments by pulsed field gel electrophoresis (PFGE), suggesting that $P$. carotovorum, like most Pectobacterium strains, encodes seven rRNA operons. Sizes of the smallest six fragments were estimated and compared with the draft genome alignment. All six fragments could be identified in the draft genome and all were roughly the same size as observed by PFGE; thus, the draft genome sequence appears to represent the majority of the genome sequence. The physical map obtained by Yap and associates (2004) also correctly represented the order of the seven $\mathrm{I}-\mathrm{CeuI}$ fragments in the WPP14 genome.

\section{Gene prediction, annotation, and comparative genomics.}

In order to minimize redundant effort and maximize consistency across genomes, we used a comparative approach to genome annotation. TBLASTN searches using the predicted proteins from the complete $P$. atrosepticum genome as queries against the draft genomes were used to identify and annotate the boundaries of all intact open reading frames (ORF). This analysis also revealed many gene fragments that would be annotated as pseudogenes if they occurred in complete genomes; however, we expect that, in these draft genomes, most of these disrupted reading frames are caused by sequencing errors arising from both known (Margulies et al. 2005) and potentially uncharacterized sources of error associated with pyrosequencing or assembly. PCR and resequencing using traditional Sanger sequencing chemistry confirmed that 10 of 10 examples were sequencing errors (data not shown). We filtered Glimmer 2 results to remove predicted ORF that overlapped with the set inherited from $P$. atrosepticum in order to identify lineage-specific ORF. Orthologs were predicted using pairwise reciprocal BLASTP searches retaining only the best hits that include greater than $60 \%$ of both predicted proteins and show greater than $55 \%$ identity. Proteins with a second match that had an $E$ value within one order of magnitude were labeled homologs rather than orthologs. Additionally, shorter (30 to $60 \%$ aligned) matches with comparable levels of sequence identity to orthologs were labeled homologs. This allowed us to accommodate gene fragments. Annotations for P. carotovorum and $P$. brasiliensis genes with $P$. carotovorum orthologs were propagated directly without further manual review. Annotations for lineage-specific genes were generated using the
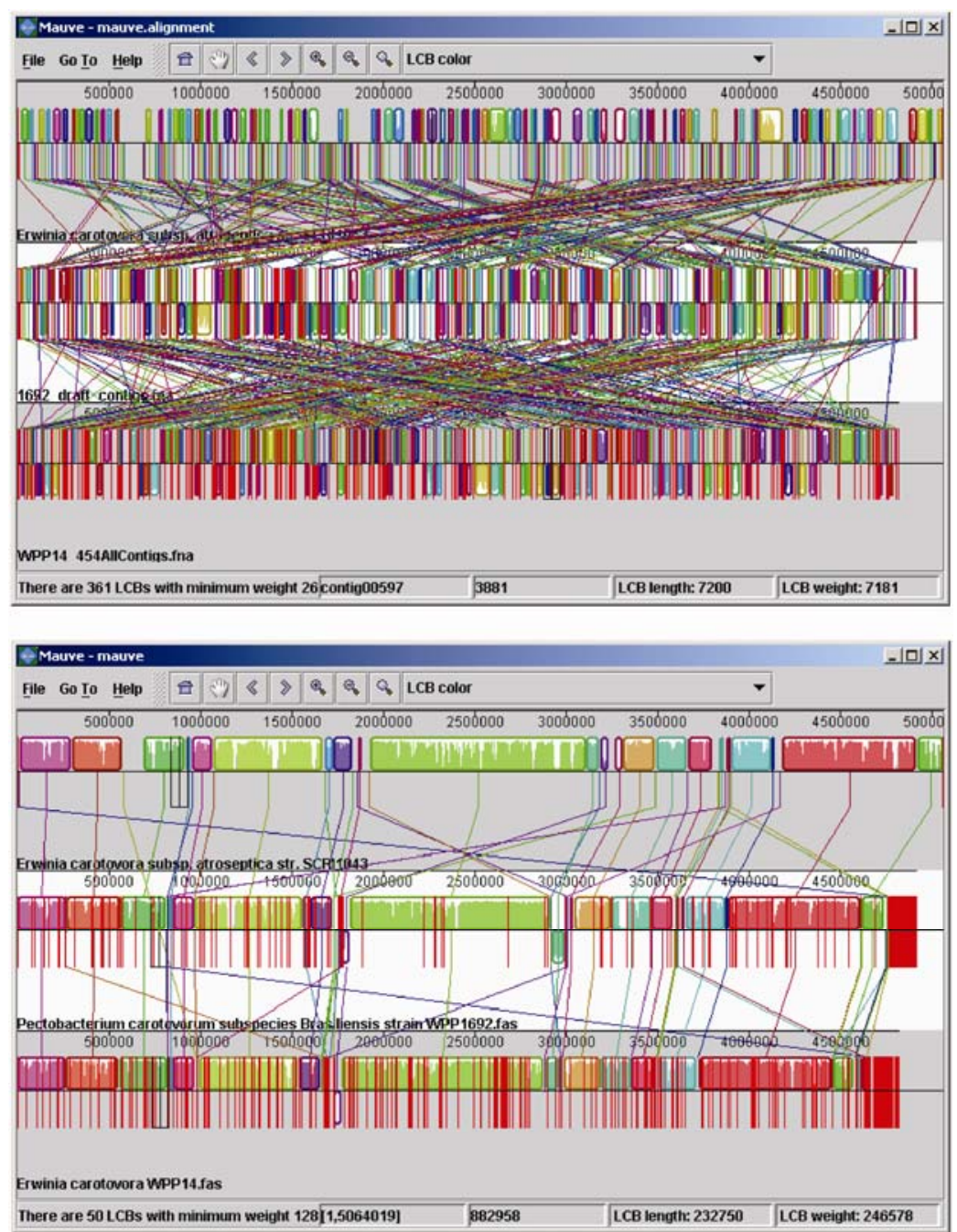

Fig. 1. Mauve alignments of the Pectobacterium atrosepticum genome and the draft genomes of P. brasiliensis and P. carotovorum before (top image) and after (bottom image) contig reordering. Each alignment has three panels, one for each genome (P. atrosepticum, P. brasiliensis, and P. carotovorum), composed of colored segments corresponding to the boundaries of locally collinear blocks with lines connecting the center of homologous blocks in each genome. Vertical red lines in the $P$. brasiliensis and $P$. carotovorum panels indicate contig boundaries. A significant number of small, unordered lineagespecific contigs appear as a dense red region at the end of the P. brasiliensis and P. carotovorum genome panels. The reduction in the number of locally collinear blocks from 361 in the top alignment to 50 in the bottom alignment and increase in average block length is clearly visible. 
RAST server. Genes found exclusively in $P$. carotovorum or $P$. brasiliensis and genes found in both but absent from $P$. atrosepticum that also had a significant match $(E$ value $>0.00001)$ to a potentially informative (did not contain "unknown," "hypothetical," "phage," "orf," or "transposase") GenPept entry were flagged for manual review by human experts. All annotations, automated and manual, and orthologs relationships were managed and distributed using ASAP (Glasner et al. 2006). The assembled contigs were also deposited in GenBank.

Alignment of the three Pectobacterium genomes using Mauve (Figs. 1 and 2) revealed that approximately $77 \%$ of the complete $P$. atrosepticum chromosome is present in $P$. brasiliensis and $P$. carotovorum. This is comparable with the fraction of core genome relative to the total pan-genome in the previous three E. coli strain comparisons (Welch et al. 2002); however, the variable fraction of the pan-genome is more evenly distributed among the three Pectobacterium strains and subset genome pairs. Approximately $5.4 \%$ of the $P$. brasiliensis and $P$. carotovorum sequences match each other but are not conserved with $P$. atrosepticum. This is close to double the amount of sequence shared by $P$. atrosepticum and either $P$. brasiliensis or $P$. carotovorum, but not both, supporting the closer relationship of $P$. brasiliensis and $P$. carotovorum observed by Ma and associates (2007). This estimate of the size of the core genome based on genome alignment is more reliable than what can be achieved by counting BLASTP-predicted homologs, in part because it includes intergenic regions and in part because it is more robust with regard to pseudogenes and sequencing errors. An extreme example is a region encoding two large (>7,000 amino acids each) predicted components of a nonribosomal synthase in $P$. atrosepticum. No homologous proteins are detected in either $P$. brasiliensis or $P$. carotovorum, even though DNA sequences homologous to almost the entire $42-\mathrm{kb}$ region are present in both draft genomes. The large number of relatively small contigs found in this region of the draft genomes suggests that this type of highly repetitive gene poses assembly problems with short pyrosequencing reads. Keeping this caveat in mind, at least 3,251 of 4,492 predicted $P$. atrosepticum genes have orthologs (or close homologs) in all three species, and an additional 177 and 192 genes have matches in P. brasiliensis or P. carotovorum, respectively. Likely sequenc- ing errors are expected to have an even greater impact on inference of orthologs between the two draft genomes, where we detect 190 to 195 conserved genes. Average amino acid identity between $P$. carotovorum and $P$. brasiliensis is higher (95\%) than observed between orthologs of either $P$. carotovorum or $P$. brasiliensis and P. atrosepticum (92\%), underscoring the closer relationship between these two lineages. We strongly suggest that users consult the multiple alignment if they are interested in conservation of a particular gene or region.

\section{Pectobacterium islands and lineage-specific islands.}

Bell and associates (2004) described 17 islands in the $P$. atrosepticum genome absent from other enterobacteria. We examined the extent to which these islands are conserved among the three Pectobacterium spp. (Fig. 3). We also defined islands that differentiate these three genomes using the Mauve alignment. For the two draft genomes, we allowed islands to span multiple ordered contigs. Frequently, small islands can be gathered into larger "variable regions" that correspond to a likely single evolutionary event, such as acquisition of a prophage, or a cluster of genes related to a common biological process, such as $\mathrm{O}$-antigen synthesis. Analysis of the functional classes (Gene Ontology [GO] terms) of genes represented in gene islands specific to one or two genomes (Fig. 4) revealed that the predicted function for genes in indels were in similar proportions to those in the core genome with, the exceptions of genes for DNA replication and genes for transcriptional regulation. The abundance of genes for phage in the indels accounts for the overrepresentation of genes for DNA replication. The abundance of unique transcriptional regulatory genes could reflect species adaptation to specific environments.

Manual review of the computational predictions and visual inspection using the Mauve alignment viewer produced Supplementary Figure 1, which describes the 42 variable regions (VR001 to VR042). This list includes both regions with a computational predicted island longer than $10 \mathrm{~kb}$ and clusters of shorter islands that collectively span a region greater than 10 $\mathrm{kb}$ in at least one of the Pectobacterium spp. Genes at the end of each island are listed, as well as putative functions for the genes encoded in the island. The $P$. atrosepticum horizontally acquired islands (HAI) identified by Bell and associates (2004)

Table 1. Summary statistics for three sequenced Pectobacterium genomes ${ }^{\mathrm{a}}$

\begin{tabular}{|c|c|c|c|}
\hline Genome & P. atrosepticum SCRI1043 & P. brasiliensis 1692 & P. carotovorum WPP14 \\
\hline Sequencing method & $\begin{array}{l}\text { Dye terminator chemistry on } \mathrm{ABI} 3700 \\
\text { automated sequencers }\end{array}$ & Two plates of 454 GS20 sequencing & $\begin{array}{l}\text { Three plates of } 454 \text { GS20 } \\
\text { sequencing }\end{array}$ \\
\hline Assembly method & $\begin{array}{l}\text { assembled using PHRAP and GAP4 for } \\
\text { finishing }\end{array}$ & Newbler (version 1.0.53.12) & Newbler (version 01.0.51.02) \\
\hline Total number of reactions & $\begin{array}{l}54,600 \text { paired-end reads (two small } \\
\text { insert libraries); } 25,800 \text { paired-end } \\
\text { reads (medium insert library); } 500 \\
\text { paired-end reads (large insert library) }\end{array}$ & 804,834 & $1,080,725$ \\
\hline Number of reads assembled & 80,900 & 782,719 & $1,057,457$ \\
\hline Approximate read length & 500 & 110 & 110 \\
\hline Total number of bases sequenced & $40,450,000$ & $86,099,090$ & $116,320,270$ \\
\hline Finished sequence & $\begin{array}{l}\text { Final closed sequence composed of } \\
106,500 \text { reads; average } 10.2 \text {-fold } \\
\text { coverage }\end{array}$ & $\begin{array}{l}\text { Unclosed sequence with } \\
\text { approximately } 17.2 \text {-fold coverage }\end{array}$ & $\begin{array}{l}\text { Unclosed sequence with } \\
\text { approximately } 23.3 \text {-fold } \\
\text { coverage }\end{array}$ \\
\hline Total number of contigs & 1 & 1,370 & 731 \\
\hline Total base pairs & $5,064,019$ & $4,918,574$ & $4,823,187$ \\
\hline Number of large contigs $(\approx>500 \mathrm{bp})$ & 1 & 143 & 272 \\
\hline Total bp in large contigs & $5,064,019$ & $4,775,163$ & $4,746,006$ \\
\hline Average contig size & na & 34,353 & 17,775 \\
\hline N50 contig size & na & 75,304 & 38,023 \\
\hline Largest contig size & na & 350,808 & 102,016 \\
\hline Number of predicted proteins & 4,492 & 4,387 & 4,245 \\
\hline Number of pseudogenes identified & 21 & nd & 150 \\
\hline Reported & Bell et al. 2004 & This study & This study \\
\hline
\end{tabular}

a Abbreviations: $\mathrm{na}=$ not available and $\mathrm{nd}=$ not determined. 
are indicated in parentheses. The variable region (VR_000) designations provide an identifier for a polymorphic region flanked by conserved chromosomes regardless of whether or not there are islands (homologous or nonhomologous) at that location. More details about the content and biological significance of these regions are described below. P. atrosepticum ORF are referred to using the designation given in Bell and associates (2004) and ORF in the draft genome sequences are indicated by their ASAP feature ID number. When orthologous ORF are present in all three genomes, only the $P$. atrosepticum ORF number is used.

\section{Many previously defined $P$. atrosepticum HAI} are not conserved in $\boldsymbol{P}$. carotovorum or $\boldsymbol{P}$. brasiliensis.

The results presented in the previous section demonstrate that, although the HAI differentiate $P$. atrosepticum from other closely related animal-associated enterobacterial genomes (Bell et al. 2004), a substantial number of genes in those regions are not essential determinants of plant pathogenicity or even the specific soft-rot phenotypes associated with Pectobacterium spp. as a group. Some of the HAI identified previously in $P$. atrosepticum are entirely absent from both $P$. brasiliensis and $P$. carotovorum, including HAI2, HAI3, HAI4, and HAI9. Although many of these are phagerelated, HAI2 includes genes for a type IV pilus as well as the $c f a$ cluster (PA0511-0614). For other HAI, parts are conserved in one or the other new genomes but not both. Our multiple alignment suggests that several have undergone rearrangements in one or more genomes. Large parts of HAI14, including the nitrogen fixation genes, are present only in $P$. atrosepticum. Both $P$. atrosepticum and $P$. brasiliensis encode metabolic genes and transporters at the same relative chromosomal position but also a phage, suggesting that this location may also be a frequent site of insertion of horizontally acquired genes. The HAI7 type IV system of $P$. atrosepticum (PA1598-1679) is replaced by two different insertions in $P$. carotovorum and $P$. brasiliensis, as expected if this is a hot spot for variation; however, $P$. brasiliensis has T4SS (AED 4454-4501) genes, as part of an apparent integrated plasmid at a different site. In contrast HAI5, HAI6, HAI8, HAI15, and HAI 17 are completely or largely conserved among all three genomes. These HAI encode exoplysaccharide and the $\mathrm{O}$ antigen (HAI5); a nonribosomal peptide phytotoxin (HAI6); the type 3 secretion system (T3SS) and HecAB agluttinin (HAI8), the $\operatorname{aggA}$ agglutination adhesion island (HAI15); and a phage insertion (HAI17).

\section{Host range determinants in Pectobacterium spp.}

Soft-rot pathogens are notorious as broad-host-range pathogens capable of decaying a broad range of monocot and dicot plants. $P$. atrosepticum is notable because it is a well-characterized narrow-host-range pathogen, found widely on potato and rarely on other solanaceous crops. In other bacterial plant pathogens, such as Xanthomonas and Pseudomonas spp., where individual strains often can infect only a few plant hosts, pathogenesis is often restricted by recognition of T3SS effectors by host plants. Thus, in these systems, in at least some cases, host range limitation is due to host recognition of

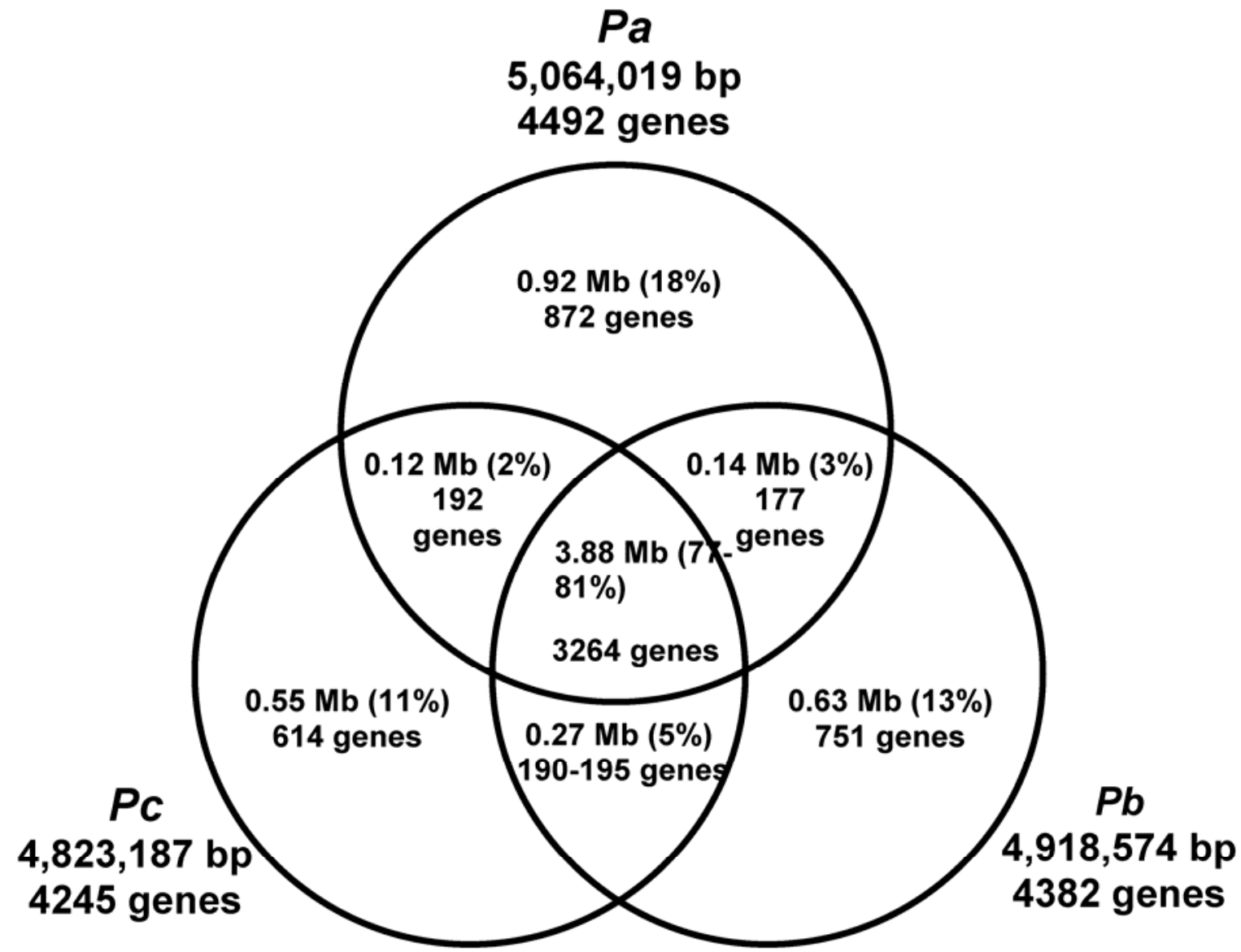

Fig. 2. Venn diagram illustrating the total amounts of shared and lineage-specific nucleotide sequence observed in the Mauve multiple alignment and predicted orthologous genes. Gene fragments resulting from likely sequence errors in the two draft genomes leads to gene count differences between species even within orthologous regions. For simplicity, the gene count for Pectobacterium atrosepticum (Pa) is shown for all shared regions except the comparison between $P$. carotovorum $(P c)$ and $P$. brasiliensis $(P b)$, where counts are shown for both species. 
genes encoded by the pathogen and not because the pathogen is lacking genes required to infect a particular host species.

The draft genome sequences of $P$. brasiliensis and $P$. carotovorum provide some insight into the host range limitations of
P. atrosepticum. Unlike Pseudomonas and Xanthomonas pathogens, the Pectobacterium spp. appear to encode few T3SS effector proteins; therefore, it is unlikely that these proteins are limiting the host range of $P$. atrosepticum to potato. In fact, the

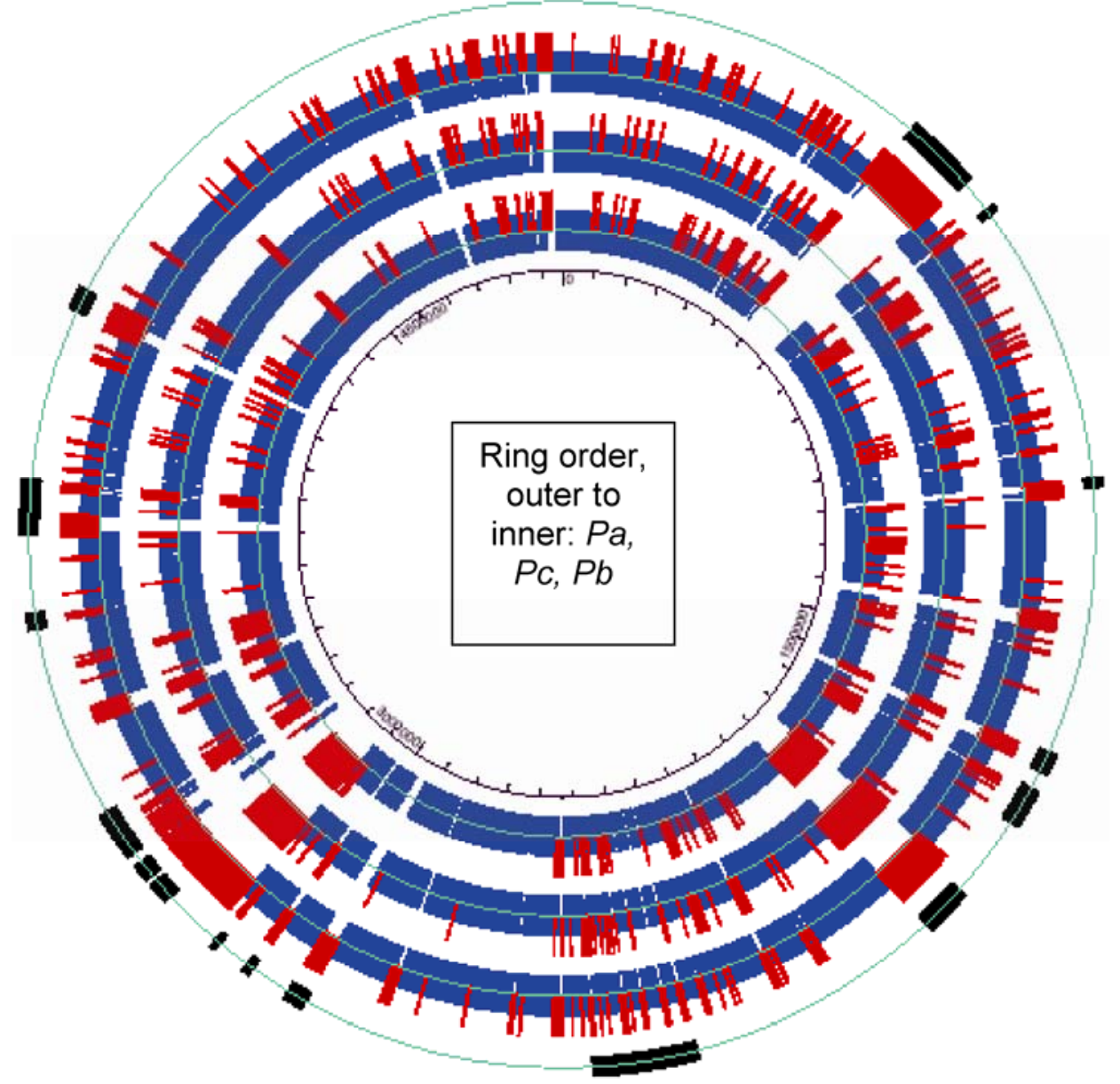

Fig. 3. Circular diagram comparing three Pectobacterium genomes. This plot is shown using the coordinate system of the complete Pectobacterium atrosepticum genome. The outer ring illustrates the position of HAI (black boxes) previously reported by Bell and associates (2004). The next ring represents the Pectobacterium atrosepticum $(\mathrm{Pa})$ genome with blue corresponding to regions conserved across all three genomes and red corresponding to regions present in only one or two of the three genomes. The next ring represents the $P$. carotovorum $(P c)$ genome and the innermost ring is the $P$. brasiliensis $(P b)$ genome.

\section{Pectobacterium genomes}

Islands from 3 genomes
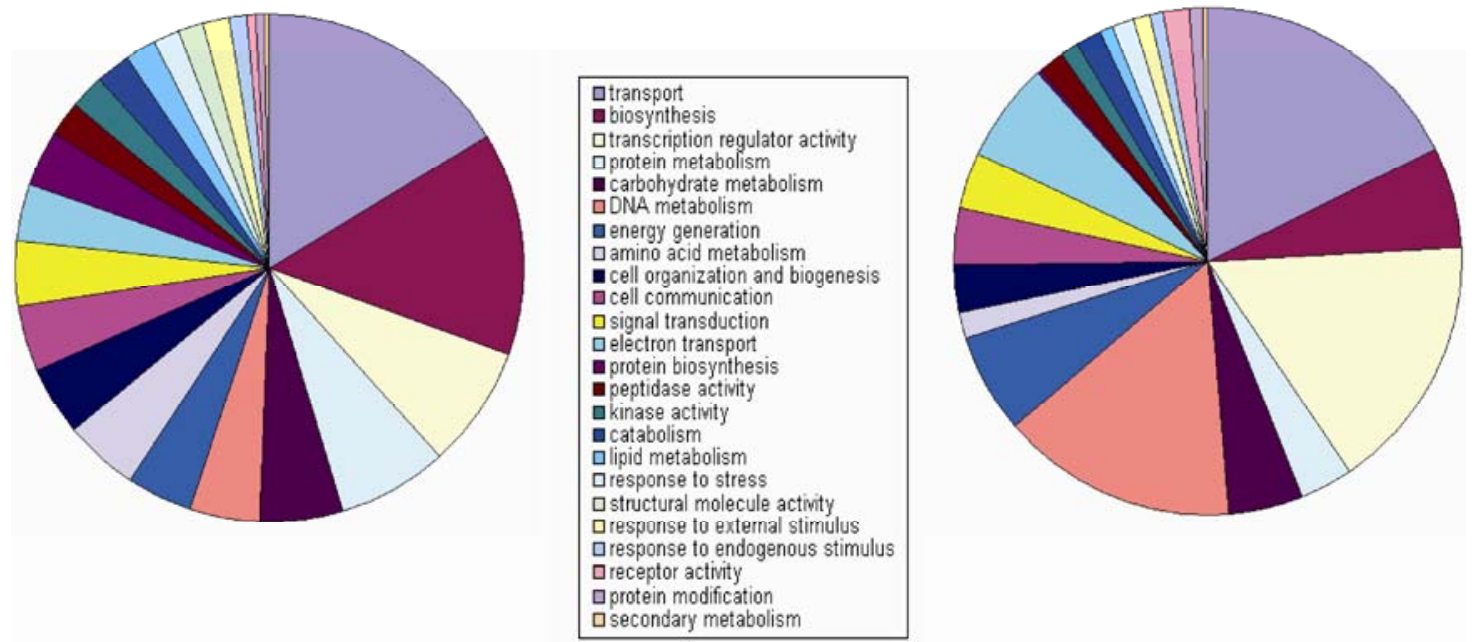

Fig. 4. Pie charts comparing Gene Ontology (GO) categories between genes found in all Pectobacterium genomes and genes unique to one of the three genomes. These pie charts show the distribution of genes in GO term categories. The chart on the left shows the distribution for all genes in all three Pectobacterium genomes and the chart on the right shows the distribution for genes unique in one of the three Pectobacterium spp. The key in the middle shows the color code for the GO term categories shown in the pie charts. 
$P$. atrosepticum T3SS is even more restricted than $P$. brasiliensis and $P$. carotovorum (see below). The most striking difference among the three species is that $P$. atrosepticum encodes genes for production of a putative phytotoxin that are lacking from the other two species. The action or recognition of this toxin by other plant species could restrict the host range of $P$. atrosepticum in a manner similar to that seen with many toxin-producing fungal pathogens. The genomes of the broad-host-range $P$. brasiliensis and $P$. carotovorum pathogens appear to encode more plant cell-wall-degrading enzymes, an additional polyketide and peptide synthetase, and several large genes of unknown function, all of which could contribute to pathogenesis on a wide range of plant species. These draft genome sequences do not clearly show whether the limitation of $P$. atrosepticum to potato is due to this pathogen lacking mechanisms required for pathogenesis on other species or due to $P$. atrosepticum inducing defenses of other species; however, the draft genomes do provide a number of high-priority targets for answering this fundamental question about soft-rot pathogenesis.

\section{Plant cell wall degradation.}

Three Pectobacterium genomes encode nearly identical type II secretion systems (T2SS) and similar sets of plant cell-walldegrading enzymes. Pectobacterium spp. wilt and rot symptoms are caused by enzymes, including pectate lyases, polygalacturonases, cellulases, and a rhamnogalacturonase, which degrade the structural components of the plant cell wall (Toth and Birch 2005). Multiple layers of regulation control synthesis of plant cell-wall-degrading enzymes in soft-rot pathogens, and the known regulators, including KdgR, ExpRI, RexZ, Crp, and H-NS, are conserved among the three Pectobacterium spp. However, there are also important differences in regulators among the three strains, with $P$. atrosepticum encoding two tandem copies of pecT and lacking an AraC-family transcriptional regulator likely to regulate the pectin methyl esterase gene pmeB. In addition, PecSM and Pir, key regulators found in Dickeya spp. (Nomura et al. 1998; Praillet et al. 1997), are not present in Pectobacterium spp.

Most of the plant cell-wall-degrading enzymes, as well as Svx, a protein of unknown function homologous to $X$. campestris AvrXca, are secreted through the T2SS (Corbett et al. 2005). All three Pectobacterium spp. encode homologous T2SS gene clusters in the same locus and all three also encode a pectate lyase and a polygalacturonase adjacent to the T2SS gene cluster. All three species also encode orthologous plant cell-wall-degrading enzymes, including 10 pectate lyases, 1 pectin lyase, 4 polygalacturonases, 2 cellulases, and 1 rhamnogalacturonase (Table 2). The soft-rot and stem-rot symptoms caused by these three species are similar and the conservation of the plant cell wall enzymes is likely to account for much of the similarity in symptoms.

Both $P$. carotovorum and $P$. brasiliensis encode putative cellwall-degrading enzymes that are not present in $P$. atrosepticum. For example, both $P$. carotovorum and $P$. brasiliensis have an indel that consists of a GntR regulatory protein homolog (ADT0003398; AED-0003444), a putative permease that could import the digested polymer (ADT-0002526; AED-0001909), a gene encoding a putative polysaccharide deacetylase (ADT-0003396; AED-0003442), and an Asp/Glu racemase (ADT-0003397; AED-0003443) which could degrade a host polymer. In addition, $P$. carotovorum encodes a cluster of enzyme homologs most closely related to Clostridium genes that may also play a role in plant cell wall degradation, including a glycoside hy-

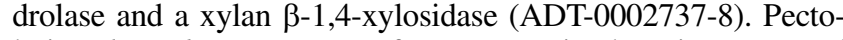
lytic Clostridium spp. are often present in decaying root and tuber crops along with Pectobacterium spp; thus, it is not surprising that there would be evidence of horizontal gene transfer between these genera. In addition to the two genes mentioned above, 11 additional $P$. carotovorum genes and two $P$. brasiliensis genes are most similar to Clostridium genes.

\section{Metalloproteases contribute \\ to Pectobacterium spp. virulence and}

multiple Pectobacterium gene islands encode novel proteases.

Pectobacterium proteases also contribute to plant cell wall degradation (Marits et al. 1999) (Table 2), and numerous proteases not found in related animal pathogens are present in Pectobacterium spp. Those proteases that have been experimentally examined are secreted via a type 1 secretion system (T1SS) (Delepelaire and Wandersman 1991; Wandersman et al. 1990). Many of the Pectobacterium proteases are also found in Dickeya spp. and a few are present in Pseudomonas syringae, suggesting that their importance in virulence may be underestimated. Plants defend against proteases by production of enzymes inhibitors (Quilis et al. 2007); the presence of numerous proteases in gene islands and the likely co-evolution of microbial peptidases and plant inhibitors are reminiscent of the co-evolution of type III effector proteins and plant disease resistance genes.

Suppression of plant defenses-the T3SS and phytotoxins.

All three species encode homologous T3SS, but Pectobacterium atrosepticum lacks hrpK. In contrast to hemibiotrophic plant pathogens such as Pseudomonas syringae and X. campestris, the T3SS of pectobacteria does not appear to be essential for growth on potato, because Pectobacterium wasabiae does not encode a T3SS but can cause disease on potato (Kim, H. S., Perna, N. T., Ma, B., and Charkowski, A. O., unpublished data). However, the T3SS does contribute to virulence of other Pectobacterium spp. (Holeva et al. 2004; Rantakari et al. 2001). Mutation of genes required for the secretion apparatus or conserved effector proteins from P. atrosepticum 1039 leads to a reduction in virulence on potato (Holeva et al. 2004). The T3SS of the three sequenced Pectobacterium spp. are homologous and in the same locus. All genes known to be required for functional T3SS are present in all three species; however, only two of the three, $P$. carotovorum and $P$. brasiliensis, elicit a type III-dependent hypersensitive response (HR) on tobacco plants, which indicates that resistance genes in tobacco recognize and respond to type III effector proteins delivered from Pectobacterium spp.

We examined the three genomes for differences in putative T3SS effectors to account for this difference. All three Pectobacterium spp. encode homologs to T3SS-secreted proteins identified in $P$. atrosepticum. Both $P$. carotovorum and $P$. brasiliensis, but not $P$. atrosepticum, encode HrpK, a T3SS-secreted protein that aids in translocation of effectors across the plant cell wall in Pseudomonas syringae (Petnicki-Ocwieja et al. 2005). Mutation of hrpK in Pectobacterium carotovorum WPP14 did not eliminate the ability of this strain to elicit the HR, and expression of the P. carotovorum WPP14 hrpK gene from a plasmid in $P$. atrosepticum did not confer HR elicitation onto $P$. atrosepticum (not shown). Thus, the lack of HR elicitation by P. atrosepticum SCRI1043 is not due to lack of $h r p K$.

\section{Other secretion systems.}

Plant-pathogenic bacteria encode numerous secretion systems that contribute to virulence in addition to the T1SS, T2SS, and T3SS. The T4SS, which is required for plasmid conjugation and which, like the T3SS, is capable of secreting proteins to the extracellular milieu and of translocating proteins into host cells, is present in different locations in $P$. atrosepticum (HAI17) and P. brasiliensis (VR028 AED4454-4501). A remnant of a T4SS is present in $P$. carotovorum (ADT-0003337). 
Currently, it is not possible to predict which proteins travel the T4SS; thus, although it appears that the P. atrosepticum T4SS may contribute to virulence (Bell et al. 2004), whether or not proteins secreted via the T4SS are conserved among $P$. atrosepticum and $P$. brasiliensis remains unknown.

The type V secretion system (T5SS), which includes autotransporter and two-partner secretion, is the simplest of the secretion systems (Henderson et al. 2004). T5SS play important roles in pathogenicity of many bacterial pathogens, including Dickeya spp. where the type V-secreted HecA hemagglutinin promotes attachment to leaf surfaces (Rojas et al. 2002). Several large proteins encoded in Pectobacterium indels are likely to be secreted via T5SS, including serine protease, hemolysin, and hemagglutinin homologs.

\section{Polyketide and peptide synthetases.}

Secondary metabolites produced by polyketide or peptide synthetases are important fitness and virulence factors in Pseudomonas syringae, where these exceptionally large proteins produce toxins active against plants and microbes as well as siderophores critical for obtaining iron. The $c f a$ locus (HAI2) of Pectobacterium atrosepticum is absent from $P$. brasiliensis and $P$. carotovorum. A $P$. atrosepticum region in HAI6 encodes genes (PA1487-1488) similar to the pore-forming phytotoxin syringomycin synthetase from Pseudomonas syringae (Bender et al. 1999) and is conserved among all three genomes but fragmented in the two draft genomes. In addition, Pectobacterium carotovorum and $P$. brasiliensis encode a polyketide or peptide synthetase system not found in $P$. atrosepticum (VR006; ADT-0002503-2509), which is most similar to ones from distantly related gram-positive bacteria and cyanobacteria, including several that produce toxins. This variability in secondary metabolite production capabilities suggests differences in how the Pectobacterium spp. interact with either their plant hosts or competing microbes, and calls for further characterization of the synthesis products, analysis of the distribution of these systems among Pectobacterium isolates, and cross-species growth inhibition assays.

Table 2. Pectobacterium plant cell-wall-degrading enzymes ${ }^{\mathrm{a}}$

\begin{tabular}{|c|c|c|c|}
\hline Enzyme & Pectobacterium atrosepticum & P. brasiliensis & P. carotovorum \\
\hline \multicolumn{4}{|l|}{ Cellulases } \\
\hline & ABL-0062482 & ADT-0000571 & AED-0001316 \\
\hline bcsZ & ABL-0064711 & ADT-0001191 & AED-0002581 \\
\hline \multicolumn{4}{|c|}{ Pectate and pectin lyases } \\
\hline pelA & ECA 4067 & AED-0002421 & ADT-0004257 \\
\hline pelB & ECA 4068 & AED-0003514 & ADT-0004256 \\
\hline pelC & ECA 4069 & AED-0002430 & ADT-0004255 \\
\hline pelI & ECA 1094 & AED-0002063 & ADT-0001495 \\
\hline pelW & ECA 2402 & AED-0001427 & ADT-0002894/5 \\
\hline pelX & ECA 4510 & AED-0002687 & ADT-0001203 \\
\hline \multirow{5}{*}{ pelZ } & ECA 4070 & AED-0002419 & ADT-0002215 \\
\hline & ECA 3112 & AED-0001793 & ADT-0000798 \\
\hline & ECA 2135 & AED-0001225 & ADT-0001743 \\
\hline & ECA 2553 & AED-0003665 & ADT-0003928 \\
\hline & Not present & AED-0002413 & Not present \\
\hline pnl & ECA 1499 & AED-0000858 & ADT-0001600 \\
\hline \multicolumn{4}{|c|}{ Polygalacturonases } \\
\hline pehA & ECA 1095 & AED-0002061 & ADT-0000261 \\
\hline pehK & ECA 3552 & AED-0003871 & ADT-0003117 \\
\hline pehN & ECA 1190 & AED-0000675 & ADT-0000300 \\
\hline pehX & ECA 3111 & AED-0001794 & ADT-0000797 \\
\hline peh fragment & ECA 0663 & Not present & Not present \\
\hline \multicolumn{4}{|l|}{ Proteases } \\
\hline & ECA 0879 & AED-0000493 & ADT-0001419 \\
\hline & ECA 1450 & AED-0003719 & ADT-0003664 \\
\hline & ECA 2007 & AED-0001126 & ADT-0001719 \\
\hline & ECA 2785 & AED-0004128 & ADT-0004008 \\
\hline & ECA 3211 & AED-0001839 & ADT-0001994 \\
\hline & ECA 2160 & AED-0001247 & ADT-0001749 \\
\hline & ECA 2074 & AED-0003289 & ADT-0002858 \\
\hline & ECA 1988 & AED-0001062 & ADT-0000521 \\
\hline & ECA 1290 & AED-0000730 & ADT-0001454 \\
\hline & ECA 4192 & AED-0002472 & ADT-0001132 \\
\hline & ECA 4397 & AED-0001980 & ADT-0003103 \\
\hline & ECA 2771 & AED-0003468 & ADT-0003994 \\
\hline & ECA 0388 & AED-0000276 & ADT-0001318 \\
\hline & ECA 0134 & AED-0004146 & ADT-0003438 \\
\hline & ECA 0133 & AED-0000078 & ADT-0001251 \\
\hline & ECA 2802 & AED-0001639 & ADT-0000726 \\
\hline & ECA 2964 & AED-0001716 & Not present \\
\hline & Not present & AED-0003397 & Not present \\
\hline & Not present & AED-0004092 & Not present \\
\hline & ECA 1004 & Not present & ADT-0003580 \\
\hline & Not present & AED-0003242 & ADT-0002516 \\
\hline & Not present & Not present & ADT-0004360 \\
\hline & Not present & AED-2871 & ADT-3651 \\
\hline & ECA 0980 & Not present & Not present \\
\hline & Not present & AED-0004079 & Not present \\
\hline & Not present & Not present & ADT-2640 \\
\hline & Not present & Not present & ADT-3526 and ADT-2470 \\
\hline
\end{tabular}

\footnotetext{
${ }^{a}$ Pectobacterium protease homologs not also present in Escherichia coli are included as potential plant cell-wall-degrading enzymes.
} 


\section{Motility and taxis.}

The Pectobacterium spp. are all capable of swimming and swarming and the entire flagellar gene cluster is encoded in one locus, similar to that of Dickeya dadantii and Yersinia spp. but differing from Escherichia coli and Salmonella enterica. Pectobacterium spp. encode two flagellin homologs. In all three Pectobacterium spp., one of the flagellin genes is located in the midst of the flagella gene cluster while the second flagellin is encoded elsewhere in a locus that contains numerous indels and rearrangements. All three flagellin genes encode a flg22 peptide sequence, suggesting that Pectobacterium spp. could activate Fls2-mediated defenses in Arabidopsis and other host plants able to recognize this particular flagellin peptide.

One hallmark that sets plant pathogens apart from animal pathogens is the large number of taxis proteins encoded in plant pathogens. Related enteric animal pathogens encode 5 to 12 methyl-accepting chemotaxis (MCP) receptors whereas, in contrast, all of the soft-rot pathogens encode over $30 \mathrm{MCP}$ receptors, with $P$. atrosepticum, $P$. carotovorum, and $P$. brasiliensis encoding 36, 39, and 34 taxis receptors, respectively. Taxis receptors function as heterotrimers of homodimers (Parkinson et al. 2005). Thus, the five receptors commonly found in $E$. coli could form up to 35 different combinations of heterotrimers, although some combinations are more likely than others due to an approximately 10 -fold higher concentration of two of the receptors compared with the other three. The high number of receptors found in plant pathogens means that thousands of combinations of heterotrimers are possible.

\section{Invertebrate interactions.}

Many enterobacteria have intimate interactions with insects and, since the early part of the 1900s, insects have been suspected of spreading soft-rot disease. For example, Pectobacterium spp. have been cultured from corn maggot eggs and mouth parts (Gnanamanickam 2006), and transgenic plants with resistance to corn maggots also suffer less from soft-rot pathogens. The related pathogen $D$. dadantii 3937 is notable in that it encodes four Bacillus thuringiensis toxin homologs, at least one of which is active against aphids (Grenier et al. 2006). The genetics of interactions between Pectobacterium spp. and invertebrates have only recently been examined. A single locus, which includes Evf and its regulator, Evr, improves survival of Pectobacterium spp. in fruit fly guts (Basset et al. 2000; Muniz et al. 2007). None of the sequenced Pectobacterium strains encode either a Bacillus toxin homolog or an Evf. $P$. atrosepticum, $P$. brasiliensis, and $P$. carotovorum all encode the regulator Evr although, in $P$. atrosepticum, evr is a pseudogene. $P$. atrosepticum may have an additional mechanism for invertebrate interactions because it encodes a cluster of genes homologous to the hemin storage proteins required by Yersinia spp. for transmission by fleas (Hinnebusch et al. 1996).

\section{Competition with other microbes-antibiotics and bacteriocins.}

Pectobacterium spp. differ in the mechanisms they use to compete with other microbes in the environment. Some strains of Pectobacterium produce the carbapenem antibiotic 1-carbapen-2-em-3-carboxylic acid (Car), an indication that the Pectobacterium sp. is in competition with potato endophytes and secondary invaders for resources (Parker et al. 1982). Of the three sequenced strains, the car genes are only found in $P$. brasiliensis. Pectobacterium strains also produce multiple forms of carotovoricin, a phage-tail-like bacteriocin which kills closely related strains and species (Nguyen et al. 2001, 2002). P. atrosepticum encodes two bacteriocin resistance pro- teins which are not homologous to each other, and only one of these two is also found in $P$. carotovorum and $P$. brasiliensis. Both $P$. carotovorum and $P$. brasiliensis encode one gene homologous to the Yersinia bacteriocin pesticin (ASAP ID ADT0002424; AED-0003952) and a second, unrelated bacteriocin homolog is adjacent to the pesticin homolog in $P$. brasiliensis (AED-0003953). No bacteriocins are apparent in the $P$. atrosepticum genome.

Variability in nutrient acquisition and metabolism.

Pectobacterium strains vary in the carbon sources they can use (Yap et al. 2004) and numerous Pectobacterium indels appear to be involved in metabolite uptake or degradation, providing a genetic explanation for some of these differences. For example, $P$. atrosepticum and $P$. brasiliensis but not $P$. carotovorum encode galactonate and gluconate metabolism islands as well as a sucrose isomerase. Thus, these $P$. atrosepticum and $P$. brasiliensis strains are likely to be able to metabolize more different, common plant sugars than $P$. carotovorum. This variation suggests that competition among Pectobacterium strains goes beyond how well they attack plants and includes which plant nutrients they are able to metabolize.

\section{A protein family unique to the soft-rot erwinia.}

A family of large proteins ranging between 515 and 732 residues was found in all of the soft-rot enterobacterial genomes but is lacking from all other genomes in GenBank. Two members of this protein family are found in $P$. atrosepticum (ECA1185 and ECA1186) and P. brasiliensis (AED-0003594 and 2989), while $P$. carotovorum encodes three members (AADT-002625, 3321, and 4109) and D. dadantii 3937 encodes one homolog (ABF-0020188). These proteins each have a conserved $\mathrm{F} 5 / 8$ type $\mathrm{C}$ domain that may aid in binding galactose (Newstead et al. 2005). Other proteins with this domain bind to cell membranes; thus, these proteins could be involved in interactions with the plant cell wall or cell membrane.

\section{Conclusions.}

We characterized the pan-genome of Pectobacterium by comparing three genomes from strains that are well separated phylogenetically within the genus. Using 454-platform pyrosequencing to a depth of approximately 20 -fold genome coverage allowed assembly into roughly 200 contigs representing approximately $95 \%$ of each draft genome. The availability of a high-quality assembled genome from a related type strain made it possible for us to align the 200 contigs of each genome into a useful chromosome assembly using the Mauve program. The genes unique to each isolate were identified and aligned, making the information most useful for genome comparison available at an affordable cost. However, without completing the genome sequences by closing gaps and resequencing regions of low coverage or ambiguous sequence, it is not possible to rule out the existence of missing or erroneous data, determine the extent of rearrangements among chromosomes, and identify extrachromosomal elements. As the use of 454 and other "next-generation" sequencing technologies increases, it is important to weigh the costs and benefits of collecting additional data such as dual-ended sequences of fragments, optical map information, or directed sequences of gaps by standard PCR or cloning methods. Currently, the costs of collecting this additional data are roughly equivalent to the costs of obtaining the initial sequence data and warrant consideration when completion of the genome is critical for comparison or interpretation of sequence data. In the case of the Pectobacterium genomes presented here, little was known about the pan-genomic content of members of this genus before this report, and analysis of partially completed genomes was sufficient to identify major 
differences between isolates that will form the basis for further characterization to see if they explain phenotypic variation.

We found that each strain differed in approximately 11 to $18 \%$ of the genome. Regulatory genes were more abundant in the class of uniquely represented genes. This diversity in gene regulatory mechanisms may reflect adaptation to specific ecological niches where each organism must respond to different environmental stimuli such as varying temperatures and alternative stressful conditions. Not surprisingly, these regulators are often clustered with other strain-specific genes, suggesting potential targets of regulation, and many of these variable genes encode products involved in metabolic processes.

A number of genomic differences that we identified might have consequences for virulence of the organisms. We found variation in the content of plant cell-wall-degrading enzymes, the most obvious players in causing the symptoms of soft-rot disease, as well as diversity in the content of genes encoding metalloproteases, which are also important for degradation of host cell walls. Each strain has unique genes for production of phytoxins, another likely determinant of host range. Differences in the secretion abilities of these organisms are suggested by variation in the presence and location of type IV (and other) secretion systems among the genomes. Each genome had a large but not fully overlapping collection of genes for motility and chemotaxis. Genes for surface proteins such as $\mathrm{O}$-antigens, pili, and adhesins showed significant variability among genomes for factors that could either suppress or trigger host defenses. A large fraction of genes that differ between these organisms are of unknown function, including a family of proteins that appears unique to the soft rot pathogens. Figuring out which of the factors identified in this study are key determinants of the phenotypic differences between these pathogens will require sequencing of additional genomes and experimental characterization of gene functions, particularly sensitive assays for even subtle roles in virulence. The $P$. atrosepticum, $P$. brasiliensis, and $P$. carotovorum isolates examined in this report represent relative extremes with respect to the phylogenetic diversity within this genus, and their genomes vary considerably in genomic content. Resolving which changes are responsible for niche specialization is challenging given the magnitude of genomic differences. Sequences of a few additional members of the genus, particularly isolates more closely related to each of the groups already sampled or isolates with similar phenotypes, would likely help pinpoint a smaller number of important factors.

\section{MATERIALS AND METHODS}

Genomic analysis of $\boldsymbol{P}$. carotovorum and $\boldsymbol{P}$. brasiliensis.

P. carotovorum strain WPP14 (Yap et al. 2004) and P. brasiliensis strain 1692 (Duarte et al. 2004) were streaked from frozen cultures onto Luria-Bertani (LB) plates. Genomic DNA was isolated (Sambrook and Russell 2001) from cultures of P. carotovorum and $P$. brasiliensis grown in LB broth in shaking incubators at 25 and $37^{\circ} \mathrm{C}$, respectively. $P$. carotovorum was sequenced in three standard runs on a 454 GS20 by 454 Life Sciences (Branford, CT, U.S.A.) and assembled with Newbler software version 1.0.51.02. P. brasiliensis was sequenced in two standard runs on a GS20 by the Washington University Genome Center and assembled with Newbler software version 1.0.53.12. Contigs were reordered using Projector 2.0 (van Hijum et al. 2005) and Mauve 2.0 (Darling 2004) which was also employed for multiple genome alignment. Primer pairs for 188 gaps in the $P$. carotovorum genome sequence were designed using Projector 2.0 and used in PCR with $P$. carotovorum genomic DNA. Selected PCR products were sequenced by standard dye-deoxy sequencing on an $\mathrm{ABI}$ capillary sequencer.
We used a combination of TBLASTN (Altschul et al. 1997) searches with predicted proteins from $P$. atrosepticum SCRI1043 (Bell et al. 2004) and Glimmer2 (Delcher et al. 1999 ) to predict ORF in the $P$. carotovorum and $P$. brasiliensis genomes. Manual inspection of predicted ORF was used to remove some ORF that overlapped other ORF and small ORF $(<250 \mathrm{bp})$ that lacked significant $\operatorname{BLASTP}(E$ value $<0.00001)$ matches against the GenPept database. We used InterProScan (Quevillon 2005) to identify protein domains in the Pectobacterium genomes and obtained GO (Ashburner et al. 2000) terms associated with each domain from the InterPro to GO term mapping available from the GO website.

Sequence data and analyses are available for download from the ASAP database (Glasner et al. 2006).

\section{Expression of $P$. carotovorum hrpK in $P$. atrosepticum.}

We PCR amplified the $h r p K$ gene from $P$. carotovorum, including a 135-bp upstream region relative to the translation start site of $h r p K$ that contains a putative HrpL-binding motif, using primers P0492 (5'-taa gag tca gga gct agt gtg gcg gag ctc agg gtt-3') and P0493 (5'-taa gct ggc gca tta gcg cga att cgg aat att $\left.\mathrm{g}-3^{\prime}\right)$. The PCR fragment was cloned into pCPP50 (Bogdanove et al. 1998), resulting in plasmid p50hrpK. This plasmid was electroporated into $P$. atrosepticum and a single ampicillin-resistant colony was isolated for hypersensitive response assays.

\section{Deletion of $h r p K$ from $P$. carotovorum.}

Regions flanking the $P$. carotovorum hrpK gene were PCR amplified with the left primer set P0504 (5'-gtg ctg gat ccg cta ata tca tca tac- $\left.3^{\prime}\right)$ and P0505 (5'-cgt act ctg cga agc ttc ccg tcc cca ttc tgc tgt tgt ca- $\left.3^{\prime}\right)$ and right primer set P0506 (5'-gga agc ttc gca gag tac gat tcc caa acc gcg cta atg c-3') and P0507 (5'gtc tge cgg atc cac gtt taa cga $\left.t-3^{\prime}\right)$. These two PCR fragments were used as templates for crossover PCR with primers P0504 and $\mathrm{P} 0507$. The 2.9-kb product was cloned into pGEMT-easy (Promega Corp., Madison, WI, U.S.A.), resulting in a plasmid pTA $\Delta h r p K \_$ABCD. A chloramphenicol resistance and GFP cassette obtained from pTAgfp::cm was cloned into the HindIII site of pTA $\Delta h r p K \_$ABCD, producing pTA $\Delta h r p K:: \mathrm{gfp}:: \mathrm{cm}$ This plasmid was electroporated into $P$. carotovorum for allelic-exchange mutagenesis following the methods described by Ried and Collmer (1987). The hrpK deletion mutation was confirmed by PCR and Southern blot analysis. Methods for electroporation, restriction endonuclease digestion, PCR, cloning, and Southern blotting were performed as described by Sambrook and Russell (2001).

\section{HR assay in Nicotiana tabacum.}

An assay for the HR was performed essentially as described in Bauer et al. (Bauer et al. 1994). Six- to seven-week-old Nicotiana tabacum cv. Xanthi leaves were infiltrated with either $P$. atrosepticum, $P$. atrosepticum with $\mathrm{p} 50 \mathrm{hrpK}, P$. carotovorum, $P c \Delta h r p K$, or water as a negative control. Plants were visually assayed for HR elicitation after $24 \mathrm{~h}$.

\section{ACKNOWLEDGMENTS}

We would like to thank the National Science Foundation Environmental Genomics Program for funding this work through award number 0412599.

\section{LITERATURE CITED}

Altschul, S. F., Madden, T. L., Schäffer, A. A., Zhang, J., Zhang, Z., Miller, W., and Lipman, D. J. 1997. Gapped BLAST and PSI-BLAST: a new generation of protein database search programs. Nucleic Acids Res. 25(17):3389-3402.

Ashburner, M., Ball, C. A., Blake, J. A., Botstein, D., Butler, H., Cherry, J. 
M., Davis, A. P., Dolinski, K., Dwight, S. S., Eppig, J. T., Harris, M. A., Hill, D. P., Issel-Tarver, L., Kasarskis, A., Lewis, S., Matese, J. C., Richardson, J. E., Ringwald, M., Rubin, G. M., and Sherlock, G. 2000. Gene ontology: Tool for the unification of biology. The Gene Ontology Consortium. Nat. Genet. 25(1):25-29.

Basset, A., Khush, R. S., Braun, A., Gardan, L., Boccard, F., Hoffmann, J. A., and Lemaitre, B. 2000. The phytopathogenic bacteria Erwinia carotovora infects Drosophila and activates an immune response. Proc. Natl. Acad. Sci. U.S.A. 97(7):3376-3381.

Bauer, D. W., Bogdanove, A. J., Beer, S. V., and Collmer, A. 1994. Erwinia chrysanthemi hrp genes and their involvement in soft rot pathogenesis and elicitation of the hypersensitive response. Mol. Plant-Microbe Interact. 7(5):573-81.

Bell, K. S., Sebaihia, M., Pritchard, L., Holden, M. T. G., Hyman, L. J., Holeva, M. C., Thomson, N. R., Bentley, S. D., Churcher, L. J. C., Mungall, K., Atkin, R., Bason, N., Brooks, K., Chillingworth, T., Clark, K., Doggett, J., Fraser, A., Hance, Z., Hauser, H., Jagels, K., Moule, S., Norbertczak, H., Ormond, D., Price, C., Quail, M. A., Sanders, M., Walker, D., Whitehead, S., Salmond, G. P. C., Birch, P. R. J., Parkhill, J., and Toth, I. K. 2004. Genome sequence of the enterobacterial phytopathogen Erwinia carotovora subsp atroseptica and characterization of virulence factors. Proc. Natl. Acad. Sci. U.S.A. 101(30):11105-11110.

Bender, C. L., Alarcon-Chaidez, F., and Gross, D. C. 1999. Pseudomonas syringae phytotoxins: Mode of action, regulation, and biosynthesis by peptide and polyketide synthetases. Microbiol. Mol. Biol. Rev. 63(2):266-292.

Bogdanove, A. J., Bauer, D. W., and Beer, S. V. 1998. Erwinia amylovora secretes DspE, a pathogenicity factor and functional AvrE homolog, through the Hrp (type III secretion) pathway. J. Bacteriol. 180(8):22442247.

Corbett, M., Virtue, S., Bell, K., Birch, P., Burr, T., Hyman, L., Lilley, K., Poock, S., Toth, I., and Salmond, G. 2005. Identification of a new quorum-sensing-controlled virulence factor in Erwinia carotovora subsp. atroseptica secreted via the type II targeting pathway. Mol. PlantMicrobe Interact. 18(4):334-342.

Darling, A. C., Mau, B., Blattner, F. R., and Perna, N. T. 2004. Mauve: Multiple alignment of conserved genomic sequence with rearrangements. Genome Res. 14:1394-1403.

Delcher, A. L., Harmon, D., Kasif, S., White, O., and Salzberg, S. L. 1999. Improved microbial gene identification with GLIMMER. Nucleic Acids Res. 27(23):4636-4641

Delepelaire, P., and Wandersman, C. 1991. Characterization, localization and transmembrane organization of the three proteins PrtD, PrtE and PrtF necessary for protease secretion by the gram-negative bacterium Erwinia chrysanthemi. Mol. Microbiol. 5(10):2427-2434.

Duarte, V., de Boer, S. H., Ward, L. J., and de Oliveira, A. M. 2004. Characterization of atypical Erwinia carotovora strains causing blackleg of potato in Brazil. J. Appl. Microbiol. 96(3):535-545.

Feil, H., Feil, W. S., Chain, P., Larimer, F., DiBartolo, G., Copeland, A., Lykidis, A., Trong, S., Nolan, M., Goltsman, E., Thiel, J., Malfatti, S., Loper, J. E., Lapidus, A., Detter, J. C., Land, M., Richardson, P. M., Kyrpides, N. C., Ivanova, N., and Lindow, S. E. 2005. Comparison of the complete genome sequences of Pseudomonas syringae pv. syringae B728a and pv. tomato DC3000. Proc. Natl. Acad. Sci. U.S.A. 102(31):11064-11069.

Gardan, L., Gouy, C., Christen, R., and Samson, R. 2003. Elevation of three subspecies of Pectobacterium carotovorum to species level: Pectobacterium atrosepticum sp. nov., Pectobacterium betavasculorum sp. Nov. and Pectobacterium wasabiae sp. nov. Int. J. Syst. Evol. Microbiol. 53:381-391.

Glasner, J. D., Rusch, M., Liss, P., Plunkett, G., Cabot, E. L., 3rd, Darling, A. Anderson, B. D., Infield-Harm, P., Gilson, M. C., and Perna, N. T. 2006. ASAP: A resource for annotating, curating, comparing, and disseminating genomic data. Nucleic Acids Res. 34:D41-45.

Gnanamanickam, S. S. 2006. Plant-Associated Bacteria. Springer, Dordrecht, The Netherlands.

Grenier, A. M., Duport, G., Pages, S., Condemine, G., and Rahbe, Y. 2006. The phytopathogen Dickeya dadantii (Erwinia chrysanthemi 3937) is a pathogen of the pea aphid. Appl. Environ. Microbiol. 72:1956-1965.

Harrison, M., Quinn, C., Ann Sells, I., and Graham, D. 1977. Waste potato dumps as sources of insects contaminated with soft rot coliform bacteria in relation to re-contamination of pathogen-free potato stocks. Potato Res. 20(1):37-52.

Henderson, I. R., Navarro-Garcia, F., Desvaux, M., Fernandez, R. C., and Ala'Aldeen, D. 2004. Type V protein secretion pathway: The autotransporter story. Microbiol. Mol. Biol. Rev. 68(4):692-744.

Hinnebusch, B. J., Perry, R. D., and Schwan, T. G. 1996. Role of the Yersinia pestis hemin storage ( $\mathrm{hms}$ ) locus in the transmission of plague by fleas. Science 273:367-370.

Holeva, M. C., Bell, K. S., Hyman, L. J., Avrova, A. O., Whisson, S. C.,
Birch, P. R. J., and Toth, I. K. 2004. Use of a pooled transposon mutation grid to demonstrate roles in disease development for Erwinia carotovora subsp atroseptica putative type III secreted effector (DspE/A) and helper (HrpN) proteins. Mol. Plant-Microbe Interact. 17(9):943950.

Joardar, V., Lindeberg, M., Jackson, R. W., Selengut, J., Dodson, R. Brinkac, L. M., Daugherty, S. C., DeBoy, R., Durkin, A. S., Giglio, M. G., Madupu, R., Nelson, W. C., Rosovitz, M. J., Sullivan, S., Crabtree, J., Creasy, T., Davidsen, T., Haft, D. H., Zafar, N., Zhou, L. W., Halpin, R., Holley, T., Khouri, H., Feldblyum, T., White, O., Fraser, C. M., Chatterjee, A. K., Cartinhour, S., Schneider, D. J., Mansfield, J., Collmer, A., and Buell, C. R. 2005. Whole-genome sequence analysis of Pseudomonas syringae pv. phaseolicola 1448A reveals divergence among pathovars in genes involved in virulence and transposition. $\mathrm{J}$. Bacteriol. 187(18):6488-6498.

Jones, J. D. G., and Dangl, J. L. 2006. The plant immune system. Nature 444:323-329.

Kettler, G. C., Martiny, A. C., Huang, K., Zucker, J., Coleman, M. L., Rodrigue, S., Chen, F., Lapidus, A., Ferriera, S., Johnson, J., Steglich, C., Church, G. M., Richardson, P., and Chisholm, S. W. 2007. Patterns and implications of gene gain and loss in the evolution of Prochlorococcus. PLoS Genet. 3(12):e231.

Ma, B., Hibbing, M. E., Kim, H.-S., Reedy, R. M., Yedidia, I., Breuer, J., Breuer, J., Glasner, J. D., Perna, N. T., Kelman, A., and Charkowski, A. O. 2007. The host range and molecular phylogenies of the soft rot enterobacterial genera Pectobacterium and Dickeya. Phytopathology 97:1150-1163.

Margulies, M., Egholm, M., Altman, W. E., Attiya, S., Bader, J. S., Bemben, L. A., Berka, J., Braverman, M. S., Chen, Y. J., Chen, Z. T., Dewell, S. B., Du, L., Fierro, J. M., Gomes, X. V., Godwin, B. C., He, W., Helgesen, S., Ho, C. H., Irzyk, G. P., Jando, S. C., Alenquer, M. L. I., Jarvie, T. P., Jirage, K. B., Kim, J. B., Knight, J. R., Lanza, J. R., Leamon, J. H., Lefkowitz, S. M., Lei, M., Li, J. Lohman, K. L. Lu, H. Makhijani, V. B., McDade, K. E., McKenna, M. P., Myers, E. W. Nickerson, E., Nobile, J. R. Plant, R. Puc, B. P., Ronan, M. T., Roth, G. T., Sarkis, G. J., Simons, J. F., Simpson, J. W., Srinivasan, M., Tartaro, K. R., Tomasz, A., Vogt, K. A., Volkmer, G. A., Wang, S. H., Wang, Y., Weiner, M. P., Yu, P. G., Begley, R. F., and Rothberg, J. M. 2005. Genome sequencing in microfabricated high-density picolitre reactors. Nature 437:376-380.

Marits, R., Koiv, V., Laasik, E., and Mae, A. 1999. Isolation of an extracellular protease gene of Erwinia carotovora subsp. carotovora strain SCC3193 by transposon mutagenesis and the role of protease in phytopathogenicity. Microbiology 145:1959-1966.

McCarter-Zorner, N. J., Franc, G. D., Harrison, M. D., Michaud, J. E., Quinn, C. E., Sells, I. A., and Graham, D. C. 1984. Soft rot Erwinia in surface and underground waters in Southern Scotland and in Colorado, United States. J. Appl. Bacteriol. 57:95-105.

McCarter-Zorner, N. J., Harrison, M. D., Franc, G. D., Quinn, C. E., Sells, I. A., and Graham, D. C. 1985. Soft rot Erwinia bacteria in the rhizosphere of weeds and crop plants in Colorado, United States and Scotland. J. Appl. Bacteriol. 59:357-368

Molina, J. M., Harrison, D., and Brewer, J. W. 1974. Transmission of Erwinia carotovora var. atroseptica by Drosophila melanogaster Meig. I. Acquisition and transmission of the bacterium. Am. Potato J. 51:245250.

Muniz, C. A., Jaillard, D., Lemaitre, B., and Boccard, F. 2007. Erwinia carotovora Evf antagonizes the elimination of bacteria in the gut of Drosophila larvae. Cell. Microbiol. 9(1):106-119.

Newstead, S. L., Watson, J. N.. Bennet, A. J., and Taylor, G. 2005. Galactose recognition by the carbohydrate-binding module of a bacterial sialidase. Acta Crystallogr. D. Biol. Crystallogr. 61:1483-1491.

Nguyen, H. A., Kaneko, J., and Kamio, Y. 2002. Temperature-dependent production of carotovoricin $\mathrm{Er}$ and pectin lyase in phytopathogenic Erwinia carotovora subsp. carotovora Er. Biosci. Biotechnol. Biochem. 66(2):444-447.

Nguyen, H. A., Tomita, T., Hirota, M., Kaneko, J., Hayashi, T., and Kamio, Y. 2001. DNA inversion in the tail fiber gene alters the host range specificity of carotovoricin Er, a phage-tail-like bacteriocin of phytopathogenic Erwinia carotovora subsp. carotovora Er. J. Bacteriol. 183(21):6274-6281.

Nomura, K., Nasser, W., Kawagishi, H., and Tsuyumu, S. 1998. The pir gene of Erwinia chrysanthemi EC16 regulates hyperinduction of pectate lyase virulence genes in response to plant signals. Proc. Natl. Acad. Sci. U.S.A. 95(24): 14034-14039.

Parker, W. L., Rathnum, M. L., Wells, J. S., Jr., Trejo, W. H., Principe, P. A., and Sykes, R. B. 1982. SQ 27,860, a simple carbapenem produced by species of Serratia and Erwinia. J. Antibiot. (Tokyo) 35(6):653-660.

Parkinson, J. H., Ames, P., and Studdert, C. A. 2005. Collaborative signaling by bacterial chemoreceptors. Curr. Opin. Microbiol. 8:116-121.

Petnicki-Ocwieja, T., van Dijk, K., and Alfano, J. R. 2005. The hrpK op- 
eron of Pseudomonas syringae pv. tomato DC3000 encodes two proteins secreted by the type III (Hrp) protein secretion system: HopB1 and HrpK, a putative type III translocator. J. Bacteriol. 187(2):649-663.

Phillips, J. A., and Kelman, A. 1982. Direct fluorescent antibody stain procedure applied to insect transmission of Erwinia carotovora. Phytopathology 72(7):898-901.

Praillet, T., Reverchon, S., and Nasser, W. 1997. Mutual control of the $\mathrm{PecS} / \mathrm{PecM}$ couple, two proteins regulating virulence-factor synthesis in Erwinia chrysanthemi. Mol. Microbiol. 24(4):803-814.

Quevillon, E., Silventoinen, V., Pillai, S., Harte, N., Mulder, N., Apweiler, R., and Lopez, R. 2005. InterProScan: Protein domains identifier. Nucleic Acids Res. 33:W116-120.

Quilis, J., Meynard, D., Vila, L., Aviles, F. X., Guiderdoni, E., and San Segundo, B. 2007. A potato carboxypeptidase inhibitor gene provides pathogen resistance in transgenic rice. Plant Biotechnol. J. 5(4):537553.

Rantakari, A., Virtaharju, O., Vahamiko, S., Taira, S., Palva, E. T., Saarilahti, H. T., and Romantschuk, M. 2001. Type III secretion contributes to the pathogenesis of the soft- rot pathogen Erwinia carotovora: Partial characterization of the hrp gene cluster. Mol. Plant-Microbe Interact. 14(8):962-968.

Ried, J. L., and Collmer, A. 1987. An nptI-sacB-sacR cartridge for constructing directed, unmarked mutations in gram-negative bacteria by marker-exchange-eviction mutagenesis. Gene 57:239-246.

Rojas, C. M., Ham, J.-H., Deng, W.-L., Doyle, J. J., and Collmer, A. 2002. $\mathrm{Hec} \mathrm{A}$ is a member of a class of adhesins produced by diverse pathogenic bacteria and contributes to the attachment, aggregation, epidermal cell killing, and virulence phenotypes of Erwinia chrysanthemi EC16 on Nicotiana clevelandii seedlings. Proc. Natl. Acad. Sci. U.S.A. 99:13142-13147.

Sambrook, J., and Russell, D. W. 2001. Molecular Cloning: A Laboratory Manual, 3rd ed. Cold Spring Harbor Laboratory Press, Cold Spring Harbor, NY, U.S.A.

Tettelin, H., Masignani, V., Cieslewicz, M. J., Donati, C., Medini, D., Ward, N. L., Angiuoli, S. V., Crabtree, J., Jones, A. L., Durkin, A. S., Deboy, R. T., Davidsen, T. M., Mora, M., Scarselli, M., Margarit y Ros, I., Peterson, J. D., Hauser, C. R., Sundaram, J. P., Nelson, W. C., Madupu, R., Brinkac, L. M., Dodson, R. J., Rosovitz, M. J., Sullivan, S. A., Daugherty, S. C., Haft, D. H., Selengut, J., Gwinn, M. L., Zhou, L., Zafar, N., Khouri, H., Radune, D., Dimitrov, G., Watkins, K., O'Connor, K. J. Smith, S., Utterback, T. R., White, O., Rubens, C. E., Grandi, G., Madoff, L. C., Kasper, D. L., Telford, J. L., Wessels, M. R., Rappuoli, R., and Fraser. C. M. 2005. Genome analysis of multiple pathogenic isolates of Streptococcus agalactiae: Implications for the microbial "pan-genome." Proc. Natl. Acad. Sci. U.S.A. 102 (39):13950-13955.

Thieme, F., Koebnik, R., Bekel, T., Berger, C., Boch, J., Buttner, D.,
Caldana, C., Gaigalat, L., Goesmann, A., Kay, S., Kirchner, O., Lanz, C., Linke, B., McHardy, A. C., Meyer, F., Mittenhuber, G., Nies, D. H., Niesbach-Klosgen, U., Patschkowski, T., Ruckert, C., Rupp, O., Schneiker, S., Schuster, S. C., Vorholter, F. J., Weber, E., Puhler, A., Bonas, U., Bartels, D., and Kaiser, O. 2005. Insights into genome plasticity and pathogenicity of the plant pathogenic bacterium Xanthomonas campestris pv. vesicatoria revealed by the complete genome sequence. J. Bacteriol. 187(21):7254-7266.

Toth, I. K., and Birch, P. R. J. 2005. Rotting softly and stealthily. Curr. Opin. Plant Biol. 8:424-429.

Toth, I. K., Pritchard, L., and Birch, P. R. J. 2006. Comparative genomics reveals what makes an enterobacterial plant pathogen. Annu. Rev. Phytopathol. 44:305-336.

Triplett, L. R., Zhao, Y., and Sundin, G. W. 2006. Genetic differences between blight-causing Erwinia species with differing host specificities, identified by suppression subtractive hybridization. Appl. Environ. Microbiol. 72(11):7359-7364.

van Hijum, S. A. F. T., Zomer, A. L., Kuipers, O. P., and Kok, J. 2005. Projector 2: Contig mapping for efficient gap-closure of prokaryotic genome sequence assemblies. Nucleic Acids Res. 33:W560-W566.

Wandersman, C., Delepelaire, P., and Letoffe, S. 1990. Secretion processing and activation of Erwinia chrysanthemi proteases. Biochimie 72(23):143-146.

Welch, R. A., Burland, V., Plunkett, G., 3rd, Redford, P., Roesch, P., Rasko, D., Buckles, E. L., Liou, S. R., Boutin, A., Hackett, J., Stroud, D., Mayhew, G. F., Rose, D. J., Zhou, S., Schwartz, D. C., Perna, N. T., Mobley, H. L., Donnenberg, M. S., and Blattner, F. R. 2002. Extensive mosaic structure revealed by the complete genome sequence of uropathogenic Escherichia coli. Proc. Natl. Acad. Sci. U.S.A. 99(26):1702017024.

Willenbrock, H., Hallin, P. F., Wassenaar, T. M., and Ussery, D. W. 2007. Characterization of probiotic Escherichia coli isolates with a novel pangenome microarray. Genome Biol. 8(12):R267.

Yap, M.-N., Barak, J. D., and Charkowski, A. O. 2004. Genomic diversity of Erwinia carotovora subsp. carotovora and its correlation with virulence. Appl. Environ. Microbiol. 70:3013-3023.

\section{AUTHOR-RECOMMENDED INTERNET RESOURCES}

The University of Wisconsin's ASAP database: asap.ahabs.wisc.edu/asap/home.php

Gene Ontology map of InterPro families: www.geneontology.org/external2go/interpro2go

RAST (Rapid Annotation using Subsystem Technology) server: rast.nmpdr.org 